\title{
CORRESPONDENCE
}

\section{Accuracy of Electrocardiography in Diagnosis of Left Ventricular Hypertrophy in Arterial Hypertension: Systematic Review}

by Daniel Pewsner, Peter Jüni, Matthias Egger, Markus Battaglia, Johann Sundström, Lucas M. Bachmann in volume 40/2007

\section{A Scientifically Based Technique}

It is correctly stated that ECG is not very informative in cases of left ventricular hypertrophy (LVH) due to essential hypertension because of its low sensitivity for this condition. The large number of indices does nothing to alter this fact. Unfortunately, the authors do not offer us any judgment about another scientific technique that is directly based on the ECG, namely, the measurement of heart-rate variability (HRV). There is a great deal of evidence supporting the hypothesis that LVH is associated, as a risk factor, with elevation of sympathetic tone ("very low frequency" [VLF] in spectral analysis) and with reduced heart-rate variability (reduction of the coefficient of variation $[\mathrm{CV}]$ and of the standard deviation of normal-to-normal intervals [SDNN]), i.e., with a tendency for the heart rate to remain constant. The greater this tendency, the worse the prognosis with regard to survival. Unfortunately, despite the good evidence that LVH is useful, it is little known in Germany, while ECG remains highly popular (and perhaps excessively so).

DOI: 10.3238/arztebl.2008.0292a

Dr. med. Manfred Doepp

Seestr. 42

83209 Prien, Germany

\section{In Reply:}

Dr. Doepp's comments prompted us to perform a PubMed literature search on this subject. We retrieved six articles evaluating heart-rate variability (HRV) in the diagnosis of left ventricular hypertrophy (LVH) (1-6). Indeed, as Dr. Doepp states, all six studies demonstrated an inverse correlation between HRV and the degree of left ventricular hypertrophy in echocardiography. Diminished HRV is thus a sign of stiffening of the heart in LVH, the severity of which is also positively correlated with the age of the patient and with the severity of arterial hypertension.

The informational value of these papers is limited by the fact that all of them are diagnostic case-control studies. In all six studies, hypertensive individuals with echocardiographically demonstrated LVH were compared to healthy control individuals. Artificial study populations of this type, in which persons in an advanced stage of disease are set against healthy persons without comorbidity, are but a poor substitute for the group of patients for whom the diagnostic technique under investigation is actually intended. We know from empirical research that such studies tend to overestimate the value of diagnostic tests to a marked extent (7). Moreover, the six studies were small ( 22 to 92 cases), which limits their value still further.

Even if the postulated correlation between low HRV and LVH were to be confirmed in larger studies involving representative populations of hypertensive patients, we are not sure whether this test would then become an established part in the diagnosis of LVH. The reason is that HRV measurement requires a long-term electrocardiogram and complex electronic analysis. The effort and expense needed for HRV measurement are thus comparable to those of echocardiography, rather than the cheap and easily obtainable ECG. Echocardiography, which is considered the gold standard for the diagnosis of $\mathrm{LVH}$, is in all likelihood of greater diagnostic value than HRV measurement even in the best case.

We therefore stick by our statement that, in the primary and secondary medical care of hypertensive patients at risk for, or already suspected of having, left ventricular hypertrophy, echocardiography should be performed as the diagnostic method of choice - even if the ECG findings are negative. DOl: 10.3238/arztebl.2008.0292b

\section{REFERENCES}

1. Alter P, Grimm W, Vollrath A, Czerny F, Maisch B: Heart rate variability in patients with cardiac hypertrophy - relation to left ventricular mass and etiology. Am Heart J 2006;151: 829-36.

2. Chakko S, Mulingtapang RF, Huikuri HV, Kessler KM, Materson BJ, Myerburg RJ: Alterations in heart rate variability and its circadian rhythm in hypertensive patients with left ventricular hypertrophy free of coronary artery disease. Am Heart J 1993;126: 1364-72.

3. Mandawat MK, Wallbridge DR, Pringle SD, Riyami AA, Latif S, Macfarlane PW et al.: Heart rate variability in left ventricular hypertrophy. Br Heart J 1995; 73: 139-44.

4. Martini G, Rabbia F, Gastaldi L, Riva P, Sibona MP, Morra di Cella S et al.: Heart rate variability and left ventricular diastolic function in paients with borderline hypertension with and without left ventricular hypertrophy. Clin Exp Hypertens 2001; 23: 77-87.

5. Piccirillo G, Bucca C, Tarantini S, Santagada E, Viola E, Durante M et al.: Left ventricular mass and heart rate variability in middle-aged and elderly salt-sensitive hypertensive subjects. Arch Gerontol Geriatr 1999; 28: 159-77.

6. Ryabykina GV, Sobolev AV, Pushina EA, Lutikova LN, Aleeva MK, Sergakova LM et al.: Influence of left ventricular hypertrophy on heart rate variability in hypertensive patients. Bratisl Lek Listy 1996; 97 : 526-30.

7. Lijmer JG, Mol BW, Heisterkamp S, Bonsel GJ, Prins MH, van der Meulen $\mathrm{JH}$ et al.: Empirical evidence of design-related bias in studies of diagnostic tests. Jama 1999; 282: 1061-6.

\section{Dr. med. Daniel Pewsner}

Institute of Social and Preventive Medicine (ISPM)

University of Bern

Finkenhubelweg 11

3012 Bern, Switzerland

Conflict of interest statement

The authors of the above letter and the reply to it state that they have no conflict of interest as defined by the guidelines of the International Committee of Medical Journal Editors. 